\title{
Passionate and engaged? Passion for inventing and work engagement in different knowledge work contexts
}

Passion for inventing

\author{
Ilona Toth, Sanna Heinänen and Kaisu Puumalainen \\ LUT School of Business and Management, LUT University, Lappeenranta, Finland
}

\begin{abstract}
Purpose - In response to the increasing interest in entrepreneurs' well-being in both the entrepreneurship and management research fields, this study builds and tests a research model on the role of entrepreneurial passion for inventing in work engagement in the context of modern knowledge work. The research argument is built on the job demands-resources model, the most commonly used frame for measuring employee well-being in work and organization psychology. The research setting in this study compares digital entrepreneurs and freelancers with traditional knowledge workers and part-time platform workers in terms of passion and engagement.

Design/methodology/approach - Using a quantitative research design, the authors collected data from 349 highly specialized knowledge workers through anonymous questionnaires. The research hypotheses were tested with linear and logit models.

Findings - The results show that entrepreneurial passion is positively related to increased job demands and work engagement and that job demands can have a positive effect on work engagement in highly complex knowledge work.

Originality/value - The study contributes to the entrepreneurship literature by expanding the analysis of entrepreneurial passion outside the entrepreneurship context and into work engagement theory by adding passion for inventing as an important motivational factor in modern knowledge work. Extant literature on the consequences of work digitalization is still scarce, and this study provides insights into successful working on digital platforms.
\end{abstract}

Keywords Entrepreneurial passion, Passion for inventing, Work engagement, Knowledge workers, Digital work platforms, Freelancers

Paper type Research paper

\section{Introduction}

The role of entrepreneurial passion (EP) in work-related well-being in modern knowledge work is rapidly emerging as an important research area as the world of work is undergoing fundamental changes. The increase in autonomous work, job crafting (Bakker et al., 2012; Berg et al., 2013) or job sculpting (Pollack et al., 2020) and continuous learning and the demand for an entrepreneurial mindset (Turner and Pennington, 2015), along with globalization and digitalization, are changing the way knowledge work is being carried out. The amount of knowledge work done virtually will continue to increase with the introduction of new modes of working, such as virtual platforms (Caballer et al., 2005), co-creation teams (Johns and Gratton, 2013) and crowdsourcing (Barnes et al., 2015). EP (Cardon et al., 2009) can be an

C Ilona Toth, Sanna Heinänen and Kaisu Puumalainen. Published by Emerald Publishing Limited. This article is published under the Creative Commons Attribution (CC BY 4.0) licence. Anyone may reproduce, distribute, translate and create derivative works of this article (for both commercial and noncommercial purposes), subject to full attribution to the original publication and authors. The full terms of this licence may be seen at http://creativecommons.org/licences/by/4.0/legalcode.

The authors would like to thank the two anonymous reviewers for their significant development suggestions. This work was supported by the Finnish Work Environment Fund under grant number 117147.

Received 24 September 2020 Revised 1 February 2021 23 March 2021 
IJEBR

27,9

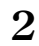

essential element of work-related well-being and successful performance in new forms of organizing knowledge work, in which the demands for autonomy and self-dependence are high and job security is low. One such form is work on digital platforms, in which commissions include the novelty aspect and contracts are made on a project basis. Wiklund et al. (2019) encourage the study of well-being in entrepreneurship research, as they believe that entrepreneurship literature and theory can significantly contribute to the widespread interest in work-related well-being.

In this study, we apply Cardon et al.'s (2009) definition of EP. "consciously accessible intense positive feelings experienced by engagement in entrepreneurial activities associated with roles that are meaningful and salient to the self-identity of the entrepreneur" (p. 517). The object or domain of passion for which a person holds intense positive feelings refers to the entrepreneurial processes of (1) inventing new products or services, (2) founding new organizations and (3) developing these organizations beyond their initial survival and success (Cardon et al., 2013). As this study's purpose is to compare four different knowledge work contexts - those of digital entrepreneurs, digital freelancers, traditional-context employees and part-time platform workers - we chose to focus solely on the domain of inventing; the domains of business founding and development are not as relevant for the two latter groups. Passion for inventing concerns activities such as scanning the environment for new market opportunities, developing new products or services and working with new prototypes (Cardon et al., 2009). Individuals with intense passion for inventing enjoy creating new product or service ideas and finding new solutions to important needs and problems. They are more creative than those with less passion for inventing (Cardon et al., 2013).

The purpose of this study is to test the relationships between entrepreneurial passion for inventing (EPI) and work-related well-being manifested as work engagement among knowledge workers in different work contexts. We use Schaufeli's (2013) revised version of the job demands-resources model and Hackman and Oldham's (1976) job design theory to build a theoretical model that investigates these relationships. We argue that having EPI serves as a motivational resource in modern knowledge work contexts and that this motivational resource is needed in complex problem-solving expert assignments, in which both the pace of work and changes at work result in more variable job demands (Downes et al., 2020). We also believe that forgoing the security of a permanent work relationship for the purpose of working on a temporary basis on digital work platforms is an additional demand for carrying out one's job successfully. We ask the following question: Is EPI an essential driver of work engagement in highly specialized knowledge work?

Our work contributes to the literature in several ways. First, it addresses the call for research on the role of passion outside the entrepreneurship context (Newman et al., 2021) by extending EP to employee contexts where working requires creating new product or service ideas and finding new solutions to important needs and problems, as identified by Cardon et al. (2013) as to what constitutes passion for inventing. We argue that passion for inventing is less context-dependent than the two other forms of passion (founding and developing), which are more directly connected with new venture creation. We believe that passion for inventing can also be experienced in other work contexts. Furthermore, we argue that as our respondents' level of passion for inventing is high, they find these processes related to inventing very enjoyable. To our knowledge, this is the first study to investigate the relationship between $\mathrm{EP}$ and work engagement in a heterogeneous knowledge work context, and we therefore fill the research gap identified by Newman et al. (2021) by discussing the implications of passion for inventing on work-related well-being in both entrepreneur and employee contexts. Second, it is vital for entrepreneurship theory to recognize the strengthening role that EPI plays in increasingly autonomous and self-managed knowledge work relationships. In addition, research on the demands of successful digital platform work is scarce, and our study adds to the literature on work digitalization. Third, our work enriches current knowledge on the antecedents of work engagement and adds to the 
understanding of employee well-being through hedonic and eudaimonic forms of work engagement, which we present as a novel contribution to work engagement literature. Although work engagement has previously been measured among many professional groups, research on work engagement focusing on a heterogeneous group of highly specialized knowledge workers is scarce.

The article begins by introducing the theoretical foundations of the study starting with the job demands-resources model (Demerouti et al., 2001) behind our research framework. We then proceed to introducing our main concepts, the concept of passion, followed by the concept of work engagement and its antecedents and outcomes. We use the model of Schaufeli (2013) to explain why we think EPI can be a motivational personal resource in knowledge work as a result of the increasing role of autonomy and self-management in complex knowledge work tasks. We then build our hypotheses regarding the relationships between EP, the demands of modern knowledge work and work engagement, also discussing the mediating effect of increased job demands on the relationship between EPI and work engagement. The article proceeds with an introduction of the chosen methodology and the results of the linear and logit models. The paper concludes with a discussion of the main findings and their theoretical implications and managerial contributions. Lastly, we present the research limitations and offer suggestions for future research.

\section{Theoretical framework and hypothesis development}

Research model

To fill the research gap identified in the introduction, we build a theoretical model based on two organizational psychology theories - the experience of work engagement and its antecedents and outcomes (Schaufeli, 2013) and Hackman and Oldham's (1976) job design theory explaining the development of work engagement. The work engagement construct relies on the job demands-resources model developed by Demerouti et al. (2001) as an alternative way of measuring employee well-being. It was originally used in employee wellbeing research to describe the relationship between burnout and disengagement. Based on this model, the working environment can be divided into job demands and job resources. Job demands are the physical, psychological, social and organizational job features that require sustained physical or psychological efforts from an employee. Job resources are the physical, psychological, social and organizational job features that help in achieving work goals, reducing job demands and stimulating personal growth, learning and development (Gruman and Saks, 2011). Schaufeli and Taris (2014) have expanded the use of the model to include the positive aspect of (work) engagement as an outcome of the model, thus emphasizing the motivational aspect of job resources.

The job demands-resources model is a heuristic model that specifies how employee wellbeing can be produced by two sets of working conditions. Job demands are the characteristics of the job that can evoke strain if they exceed an employee's adaptive capabilities, and job resources are the working conditions that the job at hand offers to individual employees. The basic idea behind the job demands-resources model is that while job demands can lead to exhausting employees' physical and mental resources, job resources are motivational and can lead to positive attitudes, behaviors and well-being. One of the central hypotheses in the job demands-resources model is that job resources can alleviate the impact of job demands on employees' well-being (Hakanen et al., 2005). Currently, the job demands-resources model is the most widely used frame in defining the antecedents and consequences of work engagement. Another modification to the model is the inclusion of personal resources as antecedents of work engagement (Schaufeli, 2013). We argue that in highly specialized knowledge work, EPI serves as an individual's personal resource because of its motivational aspect in complex problem-solving situations in which the job demands are high.

\section{Passion for inventing}


IJEBR 27,9

4

In their critical review of the job demands-resources model, Schaufeli and Taris (2014) emphasize that the model is not restricted to specific job demands or resources. This can be both a weakness and a strength of the model. Because of its heuristic nature, it is commonly used in concordance with other organizational theories, such as Hobfoll's (1989) conservation of resources theory, Bandura's (1977) social cognitive theory, Deci and Ryan's selfdetermination theory (1985) or Hackman and Oldham's (1976) job design theory. These supporting theories are needed to explain the underlying psychological processes involved with the chosen demands and resources (Schaufeli and Taris, 2014). On the other hand, the job demands-resources model can be applied to any work setting because of its flexibility.

The research model in Figure 1 summarizes the hypotheses to be tested in order to determine (1) the relationship between EPI and the specific demands of modern knowledge work (such as demand for autonomy, time pressure, job insecurity caused by freelancing and social distancing because of digitalization), (2) the relationship between EPI and work engagement and (3) the relationship between the aforementioned job demands and work engagement.

\section{Concept of passion}

The concept of passion has its roots in social psychology (Chen et al., 2009), and during the past decade, it has received increasing interest among entrepreneurship and management scholars (Pollack et al., 2020). Two overlapping but distinct theoretical approaches are typically used in examining the concept of passion: the dualistic model of passion (DMP), which distinguishes between harmonious and obsessive passion (Vallerand et al., 2003), and the EP concept, developed by Cardon et al. (2009), which focuses on passion for the entrepreneurial activities of inventing, founding and developing. The two key components of $\mathrm{EP}$ are intense positive feelings and salience to self-identity. This view is shared by both the DMP and EP. The main distinctions between the theories are that the DMP explicitly articulates the cognitive and behavioral components of passion and emphasizes how passion is internalized into one's identity, whereas EP rejects the idea of a general entrepreneurial identity and highlights the specific role identities of the inventor, the founder and the developer (Murnieks et al., 2020).

Consistent with DMP, the theory of $\mathrm{EP}$ views intense positive feelings as more enduring than just episodic emotions, reflecting liking, excitement and joy when engaging in or thinking about the target of passion (Cardon et al., 2013). Recent studies also point to other pertinent objects of passion that are relevant to entrepreneurs, such as a product (Warnick et al., 2018), hobby (Milanesi, 2018), competition or social cause (Cardon et al., 2017).

In their meta-analysis, Pollack et al. (2020) find that role-based passion has several workspecific outcomes, such as positive affect, intrinsic and extrinsic motivation, identification, organizational citizenship behavior, job satisfaction and life satisfaction. However, the relationship between role-based passion and engagement was found to be relatively weak, which can be partly explained by the small number of studies on the relationship between

Figure 1.

Research model

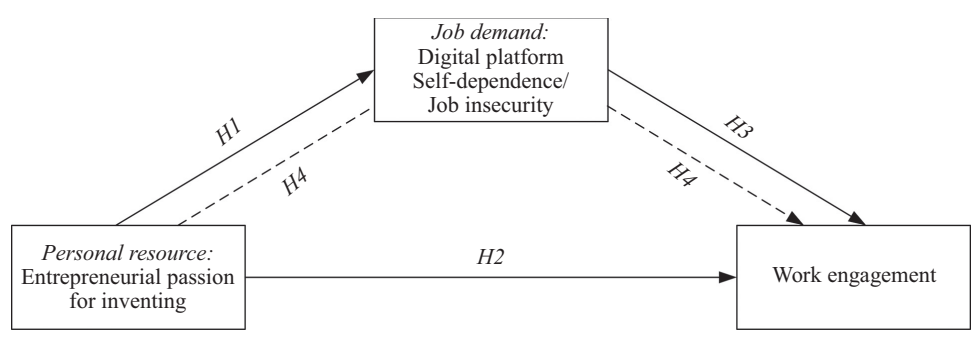


role-based passion and engagement (see also Ho and Astakhova, 2018). With the present study, we answer the call of Pollack et al. (2020) to adopt Cardon et al.'s (2009) approach for investigating passion outside the entrepreneurship domain by extending it to other relevant contexts, as suggested by Venkataraman (2019) and Carlsson et al. (2013), in which inventing new ideas and solutions is both a necessity and enjoyment. We measure and analyze rolebased passion in four such job types - digital entrepreneurs, digital freelancers, traditionalcontext employees and part-time platform workers.

\section{Concept of work engagement}

Cambridge Dictionaries [1] defines engagement as the act of being involved with something and, in relation to work, the process of encouraging people to be interested in an organization's work. The notion of work (or employee) engagement originates from Kahn's (1990) discussion of personal work-related engagement. For Kahn (1990), work-related engagement comprises three equally important psychological states: meaningfulness, safety and availability. According to Kahn (1990), personal engagement is "the simultaneous employment and expression of a person's "preferred self" in task behaviors that promote connections to work and to others, personal presence (physical, cognitive, and emotional), and active, full role performances" (p. 700).

Extant research has shown that work engagement may have positive individual and organizational consequences. Identified as one of the most significant drivers of positive work performance (Rich et al., 2010), work engagement consists of "a positive, fulfilling work-related state of mind that is characterized by vigor, dedication, and absorption" (Schaufeli et al., 2002, p. 74). Vigor refers to high levels of energy and resilience, dedication refers to strong involvement in work and absorption refers to a pleasant state of work immersion (Yalabik et al., 2015). Thus, work engagement is strongly connected with meaningful work (Macey and Schneider, 2008), which is directly related to the significance of work and to positive valence (Steger et al., 2012). Following the work of Kahn (1990), Schaufeli et al. (2002) also highlight the positive psychological and attitudinal aspects of work.

Work engagement is closely related to other work-related concepts that show positive orientation toward work, such as organizational commitment, job satisfaction and job involvement. However, Shuck et al. (2012) provide clear evidence that a structural and fundamental level of employee engagement is empirically separable from organizational commitment, job satisfaction and job involvement. Several researchers (Hallberg and Schaufeli, 2006; Rich et al., 2010; Saks and Gruman, 2014) have argued that work engagement exists as a distinct phenomenon, providing convincing evidence of the status of work engagement as an independent concept that is also separate from burnout (Schaufeli and Salanova, 2007) and workaholism (Mäkikangas et al., 2014).

\section{Entrepreneurial passion for inventing in new forms of organizing knowledge work}

Temporary and part-time work relationships have traditionally been referred to as atypical (Kiggundu, 1981) or, more recently, alternative work relationships (Spreitzer et al., 2017). Temporary organizing and working for project-based organizations are leading to an increasing number of work relationships that are no longer categorized as traditional. This shift toward new forms of organizing work is increasingly affecting knowledge workers who receive complex expert assignments. Instead of a steady monthly salary, income is collected from several sources, and working is based on an entrepreneurial type of contracting in which assignments are both short term and come from several directions. Working in such shortterm commissions is challenging for knowledge workers, as they are expected to be both flexible and ready for constant change (Kelliher and Richardson, 2011).

Independent contractors are a novel group among knowledge workers. They sell their expertise case by case or for a certain duration to an organization. This highly specialized

Passion for inventing 
IJEBR

27,9

6

group of knowledge work experts is clearly distinguishable from traditional, temporary or seasonal workers whose efforts are in demand during high seasons or other special occasions. A clear majority of independent contractors have chosen this type of work voluntarily, and in most cases, their job satisfaction is higher than that of comparison groups (Van den Born and Van Witteloostuijn, 2013). Independent contractors can also be called freelancers, who often have a permanent relationship with an organization that employs them on a regular basis (Van den Born and Van Witteloostuijn, 2013). The special characteristics of knowledge workers' freelancing have received little attention thus far in scientific research. Thus, inadequate information exists about the risks and consequences of transferring from traditional steady work relationships to freelancing. Uncertainty about the continuation of work assignments and a sufficient level of income are significant factors for workers' wellbeing (Senior, 2014), and they are challenged in this context.

Digitalization, for its part, has enabled the rise of the platform economy, in which organizing and carrying out work tasks, as well as the process of value creation, differ radically from traditional ways of arranging work. The platform economy also enables organizing new modes of working, such as interdependent co-creation or autonomous distance work, at opposite ends of the spectrum (Kenney and Zysman, 2016). Social distancing because of a lack of colleagues or working on different time zones, causing the loss of direct contacts, can be considered among the special demands of platform work.

Stenholm and Nielsen (2019) argue that EP is supported by individual competencies. Academics are increasingly interested in discovering the ways in which employees influence or shape their work conditions in contexts where these conditions are based on employees' individual abilities and are aligned with individual preferences (Bakker et al., 2016).

Based on the job demands-resources model and the hedonistic perspective (Diener, 1984) of affect-based fit, it can be postulated that individuals are generally motivated to feel good about their situation and tend to behave in ways that can sustain this positive feeling (Ho and Astakhova, 2018). Thus, individuals take actions seeking to balance their job demands with their personal resources. If individuals are highly passionate about inventing, they are more committed and persistent in pursuing complex problem-solving or opportunity-recognitionrelated tasks, and they are also more effective in accomplishing them (Pollack et al., 2020). Therefore, highly passionate individuals are more likely to feel that their current job demands are not at the level of their abilities, and they would seek more challenging tasks.

We begin by hypothesizing the following:

H1. The higher the level of EPI, the more likely a person is to seek a job with increased demands.

\section{Entrepreneurial passion for inventing and work engagement}

Basing on the motivational aspect of the job design theory, we argue that EPI further increases work engagement in the complex autonomous work tasks increasingly demanded from the individual knowledge worker in organizations. From research linking job demands and resources to work engagement (Trépanier et al., 2014) and research on the role of passion in performance (Vallerand et al., 2007) and positive organizational outcomes (Dirks and Ferrin, 2001), we assume that EP can have a positive impact on job-related positive attitudes, such as work engagement. Therefore, we seek to clarify the relationship between EPI and work engagement among knowledge workers.

In earlier research, Breugst et al. (2012) find that EP increases employees' organizational commitment, and Cardon et al. (2017) show that passion increases entrepreneurs' dedication and commitment to their ventures, their persistence in pursuing venture-related goals and activities and their ability to become and remain fully engaged in their actions. Thus, if inventing is a central element in one's identity (a person sees oneself as an inventor and 
problem-solver) and a source of enjoyment, it is more likely that the person will find modern knowledge work as engaging. The positive affect and identity centrality of passion for inventing can result in greater work dedication, more vigorous (energetic and resilient) effort in work-related tasks and a feeling of pleasant work immersion, provided that the individual's work involves tasks requiring new ideas, creativity and problem-solving. We believe that these kinds of tasks are common in modern knowledge work, and in this context, it is likely that passion for inventing serves as an antecedent of work engagement. Therefore, we hypothesize the following:

H2. EPI has a positive relationship with work engagement (UWES).

\section{Work engagement in new forms of organizing knowledge work}

Job design theory (Hackman and Oldham, 1976) focuses on both employees' psychological states and job characteristics (task variety, identity, significance, autonomy and feedback). The relevance of job characteristics to positive job attitudes has been shown in several studies (Truss et al., 2013), particularly their relevance to work engagement, such as in a metaanalysis conducted by Christian et al. (2011). Kahn (1990), the first academic to discuss personal engagement, suggests that job characteristics are important antecedents of employee attitudes and behaviors, and the job demands-resources model also emphasizes the positive connection between job characteristics and work engagement.

Traditional job design theory suggests that being able to design one's own job is motivational. Previous studies have shown a strong connection between motivation and work engagement (Schaufeli and Salanova, 2007; Van Beek et al., 2012). Crawford et al. (2010) distinguish between two types of job demands: challenges (e.g. workload, time pressure, responsibility) and hindrances (e.g. role conflict, role ambiguity). They argue that challenges tend to be positively related to work engagement, whereas hindrances tend to be negatively related to it. The positive valence of challenge demands can be explained by associated personal gains (Cavanaugh et al., 2000) or a more active style of coping (Crawford et al., 2010). Similar findings have been found in other studies, implicating that job demands may have different relationships to various outcome variables (Schaufeli and Taris, 2014); Downes et al. (2020) predict that job demand variability becomes particularly important in new forms of organizing work. We argue that choosing to work as digital entrepreneurs or freelancers and even working part-time on digital work platforms, where self-dependence is strong and job insecurity is high, could serve as either a challenge or a hindrance, depending on the individual's personal resources and motivational capabilities to cope with such demands. We further argue that as knowledge workers deal with these challenging work demands by utilizing their personal resources and succeed, a positive connection between job demands and work engagement follows as a result.

We therefore hypothesize the following:

H3. Job demands in new forms of organizing knowledge work are positively related to work engagement (UWES).

Taken together, the three hypotheses presented earlier constitute a model in which job demands could act as a mediator variable in the relationship between passion for inventing and work engagement. In other words, a higher passion for inventing could promote the selfselection of individuals into more demanding jobs, which, in turn, would trigger a higher level of work engagement.

The kind of well-being which stems from investing effort and succeeding in demanding, effortful, self-determined activities is inherent to the concept of eudaimonic well-being (Ryan and Deci, 2001) that goes beyond happiness and feelings of pleasure, which is the essence of hedonic well-being (Stephan, 2018). Waterman (1993) showed that hedonic well-being and
Passion for inventing 
IJEBR

27,9

8

eudaimonic well-being are strongly correlated but distinct dimensions of the well-being construct, both related to fulfillment of goals. However, hedonic well-being was more related to being relaxed and happy, whereas eudaimonic well-being was more related to being challenged and exerting effort, that is, actualizing one's potential.

Following the theorizing and empirical results by Schaufeli et al. (2008), work engagement can be considered one form of work-related well-being; therefore, work engagement also possibly includes both hedonic and eudaimonic elements. The hedonic element of work engagement (i.e. feeling a pleasant state of immersion/absorption while working) could result directly from the passion felt for the work activities in question, regardless of the characteristics of the work itself. On the other hand, eudaimonic work engagement (i.e., feelings of vitality and full functioning) seems to require a certain number of challenging demands. Fulfilling these demands, especially when they are autonomously set by the individual, would then turn into eudaimonic engagement.

To summarize, EPI could impact work engagement by two separate mechanisms: (1) directly, as the intense positive feeling inherent in EPI drives hedonic work engagement, and (2) indirectly, through self-selection of highly passionate individuals into more demanding activities, causing eudaimonic work engagement. Therefore, we propose the following hypothesis:

H4. The relationship of EPI with work engagement (UWES) is partially mediated by increased job demands.

\section{Research methods}

The data were collected in September 2017 and March 2018 through an online questionnaire sent to experts either working as employees in traditional organizations or contracting for two digital work platforms headquartered in Finland. The first digital platform is based on the idea of co-creation, in which complex problem-solving tasks are assigned to temporary project teams composed of members of a large expert community. These members consist of both full-time entrepreneurs and part-time platform workers who usually have a permanent work contract with another organization. The online questionnaire was sent to all experts who listed themselves as interested in the community since it was established in 2013 . The second digital platform offers autonomous expert services in translation and proofreading, in which clients submit task requests online, and the organization assigns suitable freelancers from its community. There is a high representation of women among freelancers offering translating services, and this was also the case in the second platform. The online questionnaire was sent to all experts who have engaged in activities on the digital platform since 2012. Experts working as organizational employees are members of a Finnish academic trade union. Most of them are academic engineers and architects. There are approximately 72,000 members in the trade union, and the online questionnaire was sent to 3,000 arbitrarily chosen members via a link in the trade union's newsletter in September 2017.

The data on the experts contracting on digital work platforms included 237 respondents, and the data on the members of a Finnish academic trade union included 289 respondents, of which 276 stated that they had a steady work relationship in traditional organizational settings (instead of classifying themselves as entrepreneurs or freelancers). Because of missing values in the responses, the effective sample size was 349 responses: 171 digital work platform experts and 178 traditional knowledge workers.

The data included many missing values, and the effective sample eligible for analysis was much smaller than the number of submitted questionnaires. Therefore, analyzing missing value bias was necessary, as 458 respondents completed the questions for the Utrecht Work Engagement Scale (UWES) and 401 reported a complete scale for passion. We cross-tabulated the demographic variables of gender and age and determined whether the scales included 
missing values, and we found no dependencies among these. Instead, a potential source of bias related to the samples was found. The respondents representing the co-creation platform produced more missing values than expected compared with the two other data sources. However, this can be explained by the novelty of the co-creation platform, and the main cause of missing values is the lack of experience in working on the platform, so we conclude that there is no actual bias related to missing values across the samples.

\section{Passion for inventing}

\section{Measurement}

The central concepts of EP and work engagement were measured using previously validated instruments. Cardon et al.'s (2013) EP measure consists of 13 items, and we used the first five items to reflect EPI. To measure work engagement, we used Schaufeli et al.'s (2006) shortened version of a work and well-being survey, the UWES, which comprises nine items. Some of the original items were rephrased, depending on the context for which the survey was aimed. As suggested by Sonnentag (2003) and Schaufeli et al. (2006), nine UWES items were measured as a one-dimensional engagement construct.

The respondents were asked to rate the statements based on how well the statements described the respondents and their way of working. The response scale varied from $1=$ "Not well at all" to 7 = "Extremely well." Examples of measurement items on the surveys included "Searching for new ideas for products/services to offer is enjoyable to me" and "Scanning the environment for new opportunities really excites me" to measure EPI, as well as "I am enthusiastic about my job" and "I get carried away when I am working" to measure work engagement. The full list of items is shown in Table 1.

Measurement validation for these two constructs was conducted with confirmatory factor analysis using maximum likelihood estimation for continuous variables with STATA 15.1 software. The goodness-of-fit indicators suggested a moderate fit for the measurement model $\left(\chi^{2}=192.32, \mathrm{df}=73, \mathrm{RMSEA}=0.066, \mathrm{NFI}=0.981\right)$. Table 1 summarizes the results of the measurement model with the standardized loadings and reliability indicators. Measurement reliability is assessed based on composite reliability (CR) and average variance extracted (AVE), which are calculated using factor loadings and error variances. The general acceptance levels are 0.700 for CR and 0.500 for AVE (e.g. (Diamantopoulos and Siguaw, 2000; Fornell and Larcker, 1981). It can be concluded that the measurement of the constructs meets the established criteria for reliable measurement, allowing further analysis.

\begin{tabular}{|c|c|c|c|}
\hline Item & UWES & EPI & \\
\hline I am enthusiastic about my job & 0.934 & & \\
\hline My job inspires me & 0.921 & & \\
\hline When I get up in the morning, I feel like going to work & 0.847 & & \\
\hline At my job, I feel strong and vigorous & 0.840 & & \\
\hline I am proud of the work that I do & 0.828 & & \\
\hline At my work, I feel bursting with energy & 0.817 & & \\
\hline I feel happy when I am working intensely & 0.762 & & \\
\hline I am immersed in my work & 0.725 & & \\
\hline I get carried away when I am working & 0.660 & & \\
\hline Searching for new ideas for products/services to offer is enjoyable to me & & 0.883 & \\
\hline Inventing new solutions to problems is an important part of who I am & & 0.847 & \\
\hline I am motivated to figure out how to make existing products/services better & & 0.830 & \\
\hline Scanning the environment for new opportunities really excites me & & 0.830 & Table 1. \\
\hline It is exciting to figure out new ways to solve challenging problems & & 0.817 & Standardized loadings \\
\hline Composite reliability & 0.948 & 0.924 & and reliability \\
\hline Average variance extracted & 0.671 & 0.708 & indicators \\
\hline
\end{tabular}


IJEBR 27,9

A measure for the demands of the job was created based on the reported job type and data source (pure digital platform vs traditional work). Of the total respondents, 178 were employees with a traditional type of contract, and their work status was considered the most secure and least digital. The second type of job demand involved entrepreneurs working on digital platforms (61 respondents); their job status was considered the riskiest and least secure, and they worked in a fully digital environment. The third type of job demand included freelancers operating in a digital environment and included 81 respondents. This type of job is not as demanding as the job of entrepreneurs in digital platforms but not as secure as the job of traditional workers. The final type of job demand included part-time workers on digital platforms who simultaneously have a more permanent employment contract elsewhere (29 respondents). The study included basic control variables, namely gender and age, when the hypotheses were tested. Age was measured using an ordinal scale $(1=$ less than $35,2=35$ $44,3=45-54,4=55$ or older).

\section{Analysis methods}

The hypotheses were tested using STATA 15.1 software. Because of the nature of the dependent variables, various analysis methods were applied to test the hypotheses in the research model. As the dependent variable for the first hypothesis was categorical, the relationship was analyzed with multinomial logit. The second and third hypotheses were tested with linear regression.

The final hypothesis about the mediation effect was tested using a set of linear and logistic regressions, as proposed by Iacobucci (2012).

$$
\begin{gathered}
\widehat{U W E} S=b_{01}+c E P I, \\
\widehat{p(J D)}=\frac{1}{1+e^{-\left(b_{02}+a E P I\right)}}, \\
\widehat{U W E} S=b_{03}+b J D+c^{\prime} E P I .
\end{gathered}
$$

The aforementioned three equations follow the basic logic of the seminal tests presented by Baron and Kenny (1986), with the exception that the second equation must be estimated with logistic regression instead of ordinary least squares (OLS) because of the categorical nature of the mediator variable (job demands). This makes it impossible to apply the classic Sobel (1982) test to calculate the size and statistical significance of the indirect effect. However, Iacobucci (2012) showed that the test of the indirect effect can be achieved by standardizing the coefficients $a$ from Eq. (2) and $b$ from Eq. (3). (i.e. by division with their respective standard errors, $s_{a}$ and $s_{b}$, as shown in Eq. (4)).

$$
z_{\text {Mediation }}=\frac{z_{a} z_{b}}{\sigma_{z_{a b}}}=\frac{\frac{a}{s_{a}} \times \frac{b}{s_{b}}}{\sqrt{z_{a}^{2}+z_{b}^{2}+1}} .
$$

The test statistic $z_{\text {Mediation }}$ can be compared to the standard normal distribution, where it is statistically significant at $\alpha=0.05$ level if its absolute value is larger than 1.96 . To obtain a detailed view of each of the four job demands categories, we conducted the mediator analyses separately for each pair of categories, estimating Eq. (2) with binary logistic regression.

\section{Results}

Descriptives

The descriptive statistics of our variables are shown in Tables 2 and 3. Table 2 shows the means and standard deviations for EPI and work engagement (UWES), broken down into the 


\begin{tabular}{|c|c|c|c|c|c|c|}
\hline Gender & $N$ & $\begin{array}{c}\text { EPI } \\
\text { Mean }\end{array}$ & S.D. & $\begin{array}{l}\text { UWES } \\
\text { Mean }\end{array}$ & S.D. & $\begin{array}{r}\text { Passion for } \\
\text { inventing }\end{array}$ \\
\hline Male & 225 & 5.53 & 1.08 & 5.19 & 1.09 & \\
\hline Female & 124 & 5.29 & 1.26 & 5.25 & 1.19 & \\
\hline Test statistics & $\begin{array}{l}d . f \\
347\end{array}$ & $\begin{array}{c}t \\
1.89\end{array}$ & $\begin{array}{c}p \\
0.060\end{array}$ & $\begin{array}{c}t \\
-0.480\end{array}$ & $\begin{array}{c}p \\
0.632\end{array}$ & 11 \\
\hline $\begin{array}{l}\text { Age } \\
<35 \\
35-44 \\
45-54 \\
>55\end{array}$ & $\begin{array}{r}N \\
79 \\
102 \\
83 \\
85\end{array}$ & $\begin{array}{l}\text { Mean } \\
5.53 \\
5.39 \\
5.37 \\
5.49\end{array}$ & $\begin{array}{c}\text { S.D. } \\
1.16 \\
1.02 \\
1.29 \\
1.14\end{array}$ & $\begin{array}{c}\text { Mean } \\
5.40 \\
5.15 \\
5.04 \\
5.28\end{array}$ & $\begin{array}{c}\text { S.D. } \\
1.16 \\
1.18 \\
1.09 \\
1.05\end{array}$ & \\
\hline Test statistics & $\begin{array}{c}d . f \\
3,345\end{array}$ & $\begin{array}{c}F \\
0.397\end{array}$ & $\begin{array}{c}p \\
0.756\end{array}$ & $\begin{array}{c}F \\
1.62\end{array}$ & $\begin{array}{c}p \\
0.184\end{array}$ & \\
\hline Total & $\begin{array}{c}N \\
349\end{array}$ & $\begin{array}{l}\text { Mean } \\
5.44\end{array}$ & $\begin{array}{l}\text { S.D. } \\
1.15\end{array}$ & $\begin{array}{c}\text { Mean } \\
5.21\end{array}$ & $\begin{array}{l}\text { S.D. } \\
1.13\end{array}$ & $\begin{array}{r}\text { Table } 2 . \\
\text { Descriptive } \\
\text { information by gender }\end{array}$ \\
\hline \multicolumn{6}{|c|}{ Note(s): EPI = Entrepreneurial passion for inventing, UWES = Work engagement } & $\begin{array}{r}\text { inrormation by gender } \\
\text { and age }\end{array}$ \\
\hline
\end{tabular}

\begin{tabular}{lcccrc}
\hline & DE & DF & TE & PT & Test statistic (df) \\
\hline Gender & & & & & \\
Male $N(\%)$ & $43(19 \%)$ & $41(18 \%)$ & $121(54 \%)$ & $20(9 \%)$ & $\chi^{2}=8.96(3) p=0.030$ \\
Female $N(\%)$ & $18(15 \%)$ & $40(32 \%)$ & $57(46 \%)$ & $9(7 \%)$ & \\
Age & & & & & \\
$<35 N(\%)$ & $16(20 \%)$ & $32(41 \%)$ & $24(30 \%)$ & $7(9 \%)$ & $\chi^{2}=31.68(9) p=0.000$ \\
$35-44 N(\%)$ & $18(18 \%)$ & $24(24 \%)$ & $52(51 \%)$ & $8(8 \%)$ & \\
$45-54 N(\%)$ & $8(10 \%)$ & $12(14 \%)$ & $57(69 \%)$ & $6(7 \%)$ & \\
$>55 N(\%)$ & $19(22 \%)$ & $13(15 \%)$ & $45(53 \%)$ & $8(9 \%)$ & \\
EPI Mean & 6.04 & 5.64 & 5.10 & 5.73 & $F=13.53(3,345) p=0.000$ \\
EPI S.D. & 0.971 & 0.952 & 1.20 & 0.968 & \\
UWES Mean & 5.87 & 5.65 & 4.82 & 5.03 & $F=21.43(3,345) p=0.000$ \\
UWES S.D. & 0.978 & 0.911 & 1.09 & 1.15 & \\
Total $N(\%)$ & $61(17 \%)$ & $81(23 \%)$ & $178(51 \%)$ & $29(8 \%)$ & \\
Nate & &
\end{tabular}

Note(s): $\mathrm{DE}=$ Digital entrepreneur, $\mathrm{DF}=$ Digital freelancer, $\mathrm{TE}=$ Traditional-context employee, $\mathrm{PT}=$ Parttime platform worker, EPI = Entrepreneurial passion for inventing, UWES = Work engagement

Table 3.

Descriptive information of the job types

categories of the control variables (gender and age). The gender distribution in our sample is dominated by males; out of the total of 349 respondents, only $36 \%$ are female. The average value of $\mathrm{EP}$ is higher among males (5.53) than females (5.29), but according to the independent samples $t$-test, the difference is only statistically marginally significant $(\phi=0.060)$. Females have a higher mean in work engagement (5.25) than males (5.19), but this is not statistically significant.

The sample is quite evenly distributed across four age groups - individuals under 35 years old, $23 \%$; individuals aged $35-44$ years, $29 \%$; individuals aged $45-54$ years, $24 \%$; and individuals 55 years or older, $24 \%$. EPI does not seem to vary considerably across the age groups, and the one-way ANOVA indicates no significant differences $(\phi=0.756)$. Work engagement is, on average, lowest among the group of 45-54-year-olds (5.04), whereas the highest average (5.40) is observed among the youngest respondents, but the differences are not statistically significant. 
IJEBR

27,9

Table 3 shows the job types. Employees in the traditional work context are the largest group, accounting for $51 \%$ of the sample, followed by digital freelancers $(23 \%)$, digital entrepreneurs $(17 \%)$ and part-time platform workers $(8 \%)$. Job type is significantly related to both gender and age according to the Chi-square test of independence ( $p<0.050$ for both). The majority of entrepreneurs are male and under 45 years old, whereas the majority of freelancers are female and under 45 years old. To a lesser extent, traditional knowledge workers are more likely to be male.

The lower part of Table 3 shows that traditional-context employees score, on average, lower than do the employees in other job types in EPI (5.10) with the highest within-group variation, and they have the highest average score in work engagement (4.82). Digital entrepreneurs have the highest mean scores (6.04) for EPI and UWES (5.87). Part-time platform workers stand out with high scores on passion (5.73) combined with a low level of engagement (5.03), along with the highest within-group variation. The correlation matrix of all variables is presented in Appendix, showing that the correlation between passion and engagement is positive and statistically significant $(r=0.485, p=0.000)$.

\section{Hypothesis testing}

Our dependent variable (job type) in assessing Hypothesis 1 is a categorical variable with four non-ordered categories, and we therefore apply a multinomial logit model to test H1. The higher the level of EPI, the more likely a person is to seek a job with increased demands. We use traditional-context employees as the baseline category against which the three other job types are compared. The results are shown in Table 4 . The model is statistically significant $\left(\chi^{2}=82.71, \mathrm{df}=15, p=0.000\right)$, but McFadden's pseudo $R^{2}$ indicates a rather modest fit with a value of 0.094 .

Gender has a significant positive coefficient $(b=0.60, p=0.046)$ in the comparison of digital freelancers with traditional-context employees. The relative risk ratio of 1.64 indicates that females have 1.64 times higher odds than males of choosing a digital freelancer job over a traditional employee position. Age is also significantly related to job type. It is not surprising that the highest likelihood of choosing digital-context jobs over traditional employee positions is observed in the youngest age group (i.e. those under 35 years). Interestingly, the lowest odds are among those in the age category from 45 to 54 years. This age group differs significantly from the youngest group, and the relative risk ratios indicate that the likelihood of the middle aged to be a digital entrepreneur and a freelancer is only $19 \%$ and $17 \%$, respectively, compared with that of the young.

EPI has positive and statistically significant coefficients for all three comparisons. The highest relative risk ratio is 2.64 for digital entrepreneurship. This implies that for a one-unit increase in EPI, the odds of choosing digital entrepreneurship over traditional employment are 2.64 times higher. The impact of EPI on choosing digital freelancing and digital part-time work is somewhat weaker but nevertheless statistically significant. Thus, Hypothesis 1 is supported. The predicted marginal probabilities as a function of EPI are shown in Image 1.

Hypotheses 2 and 3 focus on the impacts of EPI and job type on work engagement. The basic assumptions of OLS estimation were checked with statistical tests and graphics. First, the linearity assumption was confirmed by the scatterplots of each explanatory variable against the dependent variable, and Ramsey's RESET test for omitted variables yielded similar results $(F=1.24$, df $=3$ and 337, $p=0.295)$. Second, the White test for heteroskedasticity resulted in a Chi-square value of $45.01(\mathrm{df}=31)$ with borderline statistical significance $(\phi=0.050)$. Although a graphical examination of the residuals revealed no evidence of heteroskedasticity, we applied robust standard errors when interpreting the parameter estimates in Table 5. Multicollinearity was not an issue, as the tolerance values for EPI (0.88), gender (0.91), age categories (ranging from 0.58 to 0.59 ) and job types (ranging 


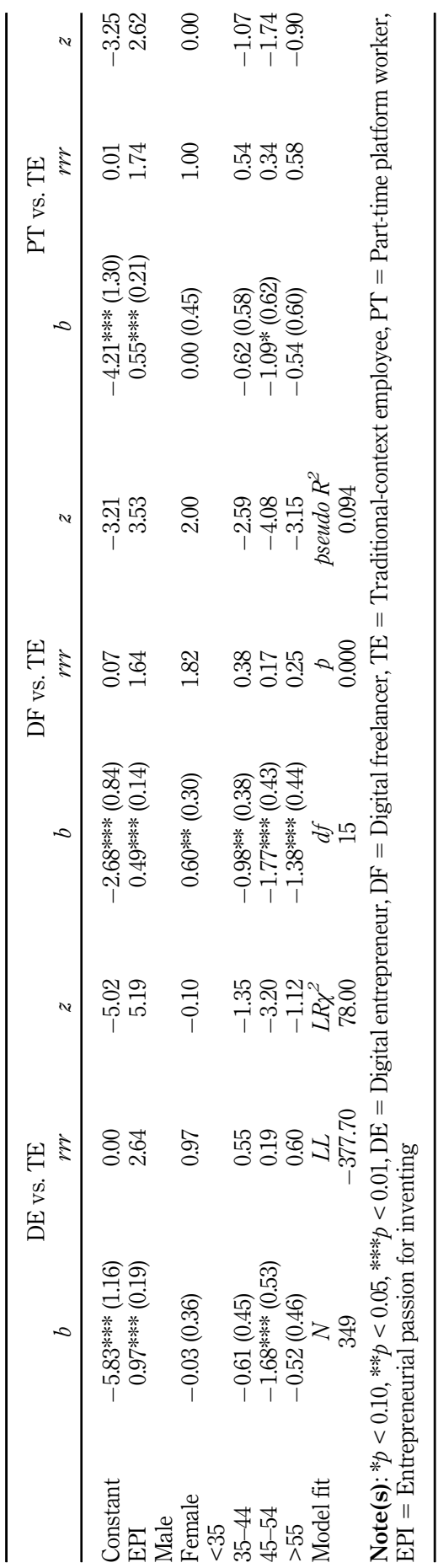

Passion for inventing

13

Table 4

Multinomial logit model explaining the job types 


\section{IJEBR \\ 27,9}

\section{4}

Figure 2.

Predicted marginal probabilities of job types as a function of EPI

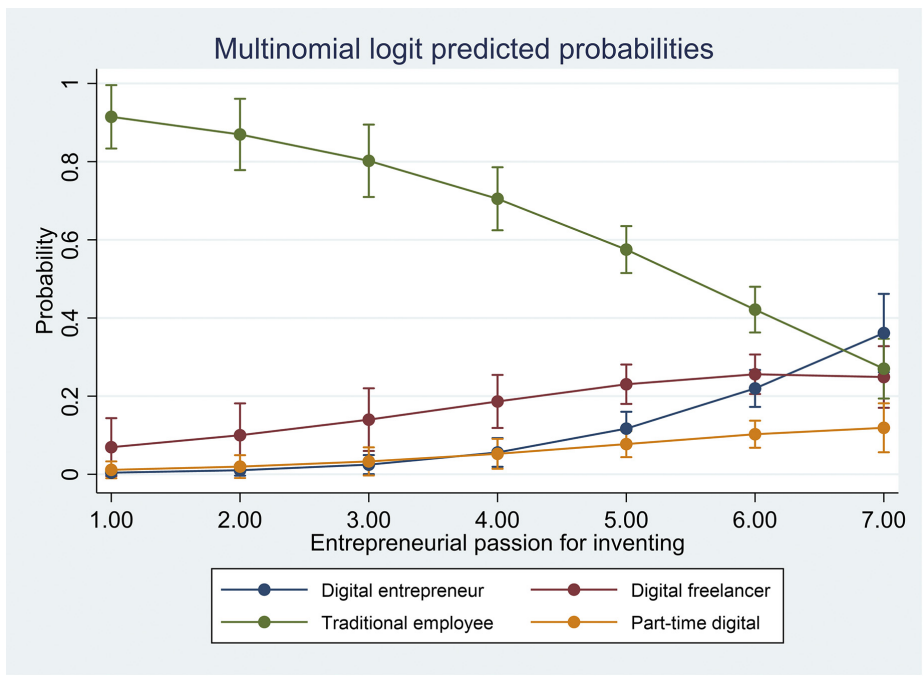

Table 5.

Linear regression model explaining UWES

\begin{tabular}{|c|c|c|c|c|c|}
\hline & $b$ & robust s.e & $T$ & $p$ & beta \\
\hline Constant & $2.71 * * *$ & 0.35 & 7.79 & 0.000 & \\
\hline $\begin{array}{l}\text { EPI } \\
\text { Male }\end{array}$ & $0.41^{* * * *}$ & 0.06 & 7.15 & 0.000 & 0.46 \\
\hline $\begin{array}{l}\text { Female } \\
<35\end{array}$ & 0.12 & 0.11 & 1.05 & 0.295 & 0.05 \\
\hline $35-44$ & -0.06 & 0.15 & -0.37 & 0.711 & -0.02 \\
\hline $45-54$ & -0.05 & 0.16 & -0.29 & 0.769 & -0.02 \\
\hline $\begin{array}{l}55 \\
\mathrm{TE}\end{array}$ & 0.08 & 0.15 & 0.53 & 0.595 & 0.03 \\
\hline $\mathrm{DE}$ & $0.65^{* * * *}$ & 0.14 & 4.52 & 0.000 & 0.22 \\
\hline DF & $0.58 * * *$ & 0.14 & 4.31 & 0.000 & 0.22 \\
\hline PT & -0.06 & 0.23 & -0.25 & 0.799 & -0.01 \\
\hline Model fit & $\begin{array}{c}N \\
349\end{array}$ & $\begin{array}{c}F \\
19.71^{* * * *}\end{array}$ & $\begin{array}{c}d f \\
8,340\end{array}$ & $\begin{array}{c}R^{2} \\
0.312\end{array}$ & $\begin{array}{r}\text { Adj. } R^{2} \\
0.296\end{array}$ \\
\hline
\end{tabular}

Note(s): $* p<0.10, * * p<0.05, * * * p<0.01, \mathrm{DE}=$ Digital entrepreneur, DF $=$ Digital freelancer, $\mathrm{TE}=$ Traditional-context employee, $\mathrm{PT}=$ Part-time platform worker, $\mathrm{EPI}=$ Entrepreneurial passion for inventing

from 0.46 to 0.73 ) were all higher than the generally applied lower limit of 0.01 . The normality of residuals was rejected based on the Shapiro-Wilk W test $(W=0.95, Z=5.913, p=0.000)$, but the graphical analysis of the histogram and normal probability plot revealed no serious violations.

The estimation results are displayed in Table 5. The model is statistically significant $(F=19.71$ with 8 and 340 degrees of freedom, $p=0.000$ ). The control variables (gender and age), job type and EPI explain $31.2 \%$ of the variation in work engagement. The effect size of each independent variable was further assessed by the eta squared values. EPI alone accounts for $18 \%$ of the variation in UWES, whereas job type accounts for $9 \%$. The explanatory power of the control variables was negligible, as the eta squared for both gender and age was as low as 0.003 . 
The parameter estimates for age and gender are all statistically nonsignificant, implying that work engagement among knowledge workers is independent of gender or age. EPI has a positive (0.41) and statistically significant $(t=7.15, p=0.000)$ coefficient, indicating that a one-unit increase in EPI increases work engagement by 0.41 units. Thus, Hypothesis 2 is supported.

Digital-context job types are compared with traditional-context jobs, and two out of the three estimated parameters are statistically significant. Digital entrepreneurs have, on average (ceteris paribus), 0.65 units higher work engagement compared with traditional employees, and digital freelancers have 0.58 units higher work engagement than traditional employees. However, part-time platform workers do not differ in engagement from traditional employees $(b=-0.06, t=-0.25, p=0.799)$. Therefore, Hypothesis 3 is supported.

The results for the mediating effect (Hypothesis 4) are shown in Table 6. The tests were conducted separately for each pair of job demand types, resulting in six comparisons, as shown in the columns of Table 6. The testing involved the estimation of Equations (1)-(3), and based on the estimated coefficients and their standard errors, the test statistic $\left(z_{\text {Mediation }}\right)$ was calculated from Equation (4).

The parameter estimates for EPI in Model 1 are all positive and statistically significant and remain so in Model 3. This indicates that the effect of EPI on UWES is positive and not fully mediated by job demands. However, based on Model 2, partial mediation is possible for comparisons DE-DF, DE-TE, DF-TE and TE-PT, as EPI has a significant effect on the job demands. However, in comparisons DE-DF and TE-PT, the effect of job demands on UWES (Model 3) is not significant, ruling out the possibility of partial mediation. Thus, a significant indirect effect is found only in two comparisons: DE-TE and DF-TE. This means that in the comparison of digital entrepreneurs or freelancers with traditional employees, a higher level of passion for inventing can encourage the individual to choose a more demanding career
Passion for inventing

\begin{tabular}{|c|c|c|c|c|c|c|c|c|}
\hline $\begin{array}{l}\text { JD categories } \\
\text { compared }\end{array}$ & & DE-DF & DE-TE & DE-PT & DF-TE & DF-PT & TE-PT & \\
\hline & $N$ & 142 & 240 & 90 & 260 & 110 & 208 & \\
\hline \multicolumn{9}{|c|}{ Model 1 (inear regression, dependent: WE) } \\
\hline \multirow[t]{3}{*}{ EPI } & $c$ & 0.412 & 0.521 & 0.485 & 0.449 & 0.258 & 0.399 & \\
\hline & $s_{c}$ & 0.073 & 0.052 & 0.109 & 0.053 & 0.099 & 0.058 & \\
\hline & $z_{c}$ & 5.59 *** & $10.09 * * *$ & $4.45^{* * * *}$ & $8.49 * * *$ & $2.60 * *$ & $6.84^{* * * *}$ & \\
\hline \multicolumn{9}{|c|}{ Model 2 (logistic regression, dependent: JD) } \\
\hline \multirow[t]{3}{*}{ EPI } & $a$ & 0.472 & 0.906 & 0.294 & 0.437 & -0.176 & -0.628 & \\
\hline & $s_{a}$ & 0.185 & 0.172 & 0.224 & 0.132 & 0.219 & 0.210 & \\
\hline & $z_{a}$ & $2.55^{* * *}$ & $5.27^{* * * *}$ & 1.32 & $3.3^{* * *}$ & -0.800 & $-2.99 * * *$ & \\
\hline \multicolumn{9}{|c|}{ Model 3 (inear regression, dependent: WE) } \\
\hline \multirow[t]{3}{*}{ EPI } & $c^{\prime}$ & 0.406 & 0.445 & 0.434 & 0.395 & 0.271 & 0.402 & \\
\hline & $s_{c^{\prime}}$ & 0.076 & 0.053 & 0.105 & 0.052 & 0.095 & 0.060 & \\
\hline & $z_{c}$ & $5.38 * * *$ & $8.39 * * *$ & $4.15^{* * *}$ & $7.6 * * *$ & $2.84 * * *$ & $6.75^{* * *}$ & \\
\hline \multirow[t]{3}{*}{ JD } & $b$ & 0.053 & 0.632 & 0.703 & 0.612 & 0.645 & 0.048 & \\
\hline & $s_{b}$ & 0.149 & 0.148 & 0.217 & 0.129 & 0.205 & 0.203 & \\
\hline & $z_{b}$ & 0.36 & $4.22 * * *$ & $3.23 * * *$ & $4.75^{* * *}$ & $3.14 * * *$ & 0.24 & \\
\hline \multicolumn{9}{|c|}{ Mediation effect } \\
\hline Effect size & $z_{a} z_{b}$ & 0.918 & 22.24 & 4.26 & 15.68 & -2.51 & -0.718 & \\
\hline Collected s.e & & 2.76 & 6.83 & 3.63 & 5.87 & 3.39 & 3.16 & Table 6 \\
\hline$z_{\text {mediation }}$ & & 0.332 & $3.26 * * *$ & 1.17 & $2.67 * * *$ & -0.741 & -0.227 & Mediation test results \\
\hline
\end{tabular}


IJEBR

27,9

path, which, in turn, can result in higher work engagement, as the individual is trying to meet the demands. Therefore, Hypothesis 4 is supported.

\section{Common method bias and robustness check}

Our research model is mainly based on objective items, such as age, gender, and job type. However, passion for inventing and work engagement were measured with self-assessments. While this is a common procedure when evaluating abstract concepts, such as passion and engagement, it can easily result in common method bias, in which false internal consistency can affect the research results. Given these concerns, we conducted a robustness check, as recommended by Podsakoff and Organ (1986). We also ensured that no reverse causality exists between our concepts. Comparing the means across two time points helps visualize stability in our concepts over time.

A follow-up survey was conducted six months after the baseline survey and was targeted only at knowledge workers who gave permission for the follow-up. A robustness check for our analyses was possible with 50 observations regarding platform-based knowledge workers. The relationships between engagement and passion for inventing were analyzed with linear regression using engagement measured in the follow-up as a dependent variable and passion for inventing measured in the baseline as an independent variable. The results suggest a significant relationship, as the standardized coefficient for passion was $\beta=0.311$ $(p=0.015)$. EP was also analyzed across the time points. A comparison of the distributions between the baseline and follow-up showed similar distributions $(t=0.169, p=0.866)$. The follow-up data did not include traditional knowledge workers, but the mean values of passion in the second survey were approximately the same as those measured in the first survey among the different types of knowledge work.

\section{Discussion}

In response to the growing interest in the changing context of knowledge work and the increase in alternative work arrangements (Hubner et al., 2020; Spreitzer et al., 2017), the present study emphasizes the importance of EPI in the development of work engagement in diverse knowledge work contexts. There is a positive gain cycle between antecedent determinants and the consequent outcomes of work engagement (Hakanen et al., 2008; Tims and Bakker, 2010), which makes work engagement such a significant element in worker wellbeing. Trépanier et al. (2014) have studied how job demands and resources are related to burnout and work engagement by using the DMP. However, to the best of our knowledge, research linking EP and work engagement has not been conducted previously (Ho and Astakhova, 2018).

According to Hauff et al. (2020), employee well-being is important for organizations not just because it is a goal per se but because several studies have established that increased employee well-being, especially work engagement, is directly and indirectly linked with organizational performance. Hauff et al. argue that employee well-being is a key mechanism for organizational effectiveness. From the employee perspective, increasing different types of job demands may have positive effects on well-being, manifesting itself as work engagement (Harju et al., 2021). Also Schaufeli et al. (2008) have previously theorized that work engagement represents one form of work-related well-being. In previous research, work engagement, together with other concepts describing positive organizational behavior, has been connected with eudaimonic well-being (De Simone, 2014; Grant et al., 2007). However, the topic is rarely discussed in the work engagement literature. We argue that both hedonic and eudaimonic elements of well-being can be present when experiencing work engagement. Based on our analysis results, hedonic work engagement (feeling a pleasant state of immersion/absorption while working) can result directly from being passionate about work 
activities, followed by the fulfillment of challenging work goals, which then results in eudaimonic work engagement (feelings of vitality and absorption).

Our first hypothesis focused on the connection between high EPI levels and a tendency to seek more demanding work roles. Our results show higher mean values for passion for inventing with digital entrepreneurs and freelancers. It seems that EPI leads to work engagement and thus serves as a motivational (Hackman and Oldham, 1976) and personal resource (Schaufeli, 2013), especially in the digital platform context. We interpret this as a tendency for people with high levels of EP to be more interested, by nature, in inventing new ideas and solutions, as well as in engaging in complex problem-solving work tasks; therefore, they choose more challenging work roles, such as entrepreneurship or freelancing, which require autonomy and responsibility for defining their work resources and time management. We further speculate that highly specialized knowledge workers who choose to contract temporarily on digital platforms are, again, by nature, passionate and engaged in their work tasks, which is why they choose to tolerate the uncertainty and ambiguity of working in these project-based work contracts. These arguments are supported by the results of testing Hypothesis 4, which suggested that increased job demands mediate the relationship between passion for inventing and work engagement. This implies that individuals with higher levels of motivational personal resources, such as EPI can find further motivation and become more engaged in their work through increased job demands.

We used the job demands-resources model (Demerouti et al., 2001) to explain why passion for inventing can serve as a resource in complex problem-solving knowledge work. The positive connection between passion for inventing and work engagement confirmed our second hypothesis, indicating that knowledge workers' work engagement is partly driven by EPI in different types of contexts, including those outside the entrepreneurial context (Newman et al., 2021). While we expected that digital entrepreneurs and freelancers would have higher values for passion for inventing compared with traditional workers, it was interesting to discover that they also had higher values for work engagement. Thus, our third hypothesis about the positive relationship between job demands and work engagement was also supported.

We consider digital entrepreneurship to be the most challenging knowledge work context in our study, in which job demand variability is the highest (Downes et al., 2020). Based on Crawford et al.'s (2010) distinction, we argued that job demands in new forms of organizing work would more likely act as challenges (rather than hindrances) and be connected with associated personal gains. Together with the fact that the level of work engagement does not differ between traditional employees and part-time platform workers, it seems that knowledge workers in digital-context job types have more resiliency in dealing with increased job demands and associate this type of working with personal gains, such as autonomy, flexibility and the possibility for diverse project assignments. This is consistent with the findings of Hessels et al. (2017) that self-employed freelancers and entrepreneurs experience less work-related stress and more satisfaction with their work because they have greater job control. Part-time platform workers seem to prefer the best of both worlds, although this might mean increased workloads and occasionally giving up some free time.

It is worth noting that the low representation of middle-aged knowledge workers in digital entrepreneur or freelancer job types was surprising. This phenomenon was irrespective of gender. We can only speculate that the reason for this could be a greater appreciation for work-family life balance.

\section{Conclusions}

\section{Theoretical implications}

As our main contribution, the results of our theoretical model provide new insights into the effect of EP on employee well-being manifested as work engagement. The power of passion in

Passion for inventing 
IJEBR

27,9

modern autonomous and highly specialized knowledge work opens interesting avenues for the inclusion of entrepreneurship theory in work and organization studies. By integrating the entrepreneurship literature with a frame used for analyzing employee well-being in work and organizational psychology, we move beyond looking at EP solely as a concept to be studied among entrepreneurs and freelancers, as suggested by Newman et al. (2021).

Previously, the behavioral consequences of EP have mainly been studied in the context of entrepreneurship. As a secondary contribution, we introduce the categorization of modern knowledge workers with job type variability based on the level of entrepreneurial activity they face in their work role. We show that the level of EP can serve as an indicator of the job type a person is interested in and most suitable for. Comparing passion for inventing and work engagement in four different job types gives us further insights into the differences in how people react to challenging work conditions. Given the challenge of studying EP in different domains, we only examine passion for inventing, as we believe it is more relevant in diverse knowledge work contexts than the other two dimensions of Cardon et al.'s (2013) measure.

The present study contributes to the extant literature on work engagement by acknowledging EP as an antecedent of work engagement, especially in modern knowledge work. We also test the relationship between job demands and work engagement and find a positive connection between high job demands and work engagement in new forms of organizing knowledge work. In the revised model of the job demands-resources model (Schaufeli and Taris, 2014), this connection was not tested. In addition, the presence of both direct and indirect effects of EPI to work engagement suggests that both hedonic and eudaimonic elements of well-being can be present in work engagement. This is a novel and interesting addition to work engagement theory.

Our contribution to the organizational literature is significant, as a growing number of employees can be classified as knowledge workers (i.e. employees who use knowledge for higher productivity and performance; Davenport and Cantrell, 2002; Dul et al., 2011), either as independent contractors or as employees in organizations. We also build on the literature on work digitalization by introducing the job type classification for digital platforms. Comparing the established relationships between job types offers interesting avenues for future research in the context of new modes of working.

\section{Practical implications}

Our research results are valuable to both human resource management personnel in traditional organizations and digital platform providers worldwide. In traditional organizations, autonomy and complex problem-solving situations are also becoming more frequent.

Schneider et al. (2018) have established that organizational practices strongly correlate with workforce engagement, and Hubner et al. (2020) have explained that experiencing meaningfulness in work leads to identifying with the (entrepreneurial) firm and building affective commitment. These ideas are in line with the concept of intrapreneurship (Moriano et al., 2014) and can lead to entrepreneurial types of contributions (Hubner et al., 2020) in the employing organization. With the assistance of passionate and engaged employees, the chances of tackling the challenges of the fast-paced contemporary economy and gaining a competitive advantage become more likely. We have established in this study that high levels of EPI are related to high levels of work engagement. This finding could be significant for organizations operating mainly with traditional work contracts. We suggest considering the introduction of an entrepreneurial attitude to employees through training, encouragement and mentoring.

For digital platform providers, building a virtual community in which independent contractors are excited about challenging problems and motivated to engage with the 
platforms' operations is crucially important. Our study indicates that digital platform providers can benefit from EPI among their contractors, as it leads to positive results, such as work engagement. The connection between work engagement and performance has been established in several studies (Bakker and Demerouti, 2008; Gruman and Saks, 2011; Rich et al., 2010).

Limitations and future research directions

As with all studies, this work also has limitations. Our measurements were partly based on self-evaluation and may thus be affected by common method bias (Chang et al., 2010). In addition, our study mainly focused on a cross-sectional survey in which we could only show the relationships between our concepts. We addressed this by performing a robustness check to show that work engagement at time 2 was affected by passion for inventing at time 1 among digital entrepreneurs and freelancers. Still, further longitudinal studies are needed to enforce our findings. Another suggestion for future research along these lines would be to measure EP among, for example, recently graduated university students and then determine a few years later whether the high levels of EP at time 1 could explain the students' career choice at time 2. Future studies could also test whether the relationship between passion for inventing and work engagement is similar in different relevant occupational groups.

Another bias in our sample was in our respondents' age profiles. Although our sample was quite evenly distributed across age groups, traditional employees were significantly older than the members of other job type groups. However, age as a control variable was not statistically significant in our sample.

We focused on EPI because of the creative knowledge work context, but other domains of passion could also be relevant determinants of work engagement in other contexts; for example, passion for a social mission or an environmental cause could be an important predictor of engagement in the social and sustainable business context. It is true that we still do not know enough about what truly drives highly specialized knowledge workers to fully engage in their work context. We also made the presumption that digital entrepreneurs, digital freelancers and part-time platform workers in this study see their work as an opportunity rather than a necessity. Future studies should consider the relevance of this difference.

Based on the results, we suggested as a new contribution to work engagement theory that both hedonic and eudaimonic elements of well-being can be present in work engagement. As these two forms of well-being are intensively discussed in the well-being literature, future research could examine this suggestion more closely and study the role of hedonic and eudaimonic work engagement and whether there are differences between the determinants and outcomes of these two types of work engagement.

Finally, research on modern knowledge work is scarce. We suggest looking more deeply into combining other issues of entrepreneurship theory and organizational research, as the importance of an entrepreneurial attitude among knowledge workers will continue to increase in the near future.

Note

1. http://dictionary.cambridge.org/dictionary/english/engagement.

\section{References}

Bakker, A.B. and Demerouti, E. (2008), "Towards a model of work engagement", Career Development International, Vol. 13 No. 3, pp. 209-223, doi: 10.1108/13620430810870476.
Passion for inventing 
IJEBR

27,9
Bakker, A.B., Tims, M. and Derks, D. (2012), "Proactive personality and job performance: the role of job crafting and work engagement”, Human Relations, Vol. 65 No. 10, pp. 1359-1378, doi: $10.1177 / 0018726712453471$.

Bakker, A.B., Rodríguez-Muñoz, A. and Sanz Vergel, A.I. (2016), "Modelling job crafting behaviours: implications for work engagement”, Human Relations, Vol. 69 No. 1, pp. 169-189, doi: 10.1177/ 0018726715581690.

Bandura, A. (1977), "Self-efficacy: toward a unifying theory of behavioral change", Psychological Review, Vol. 84 No. 2, pp. 191-215, doi: 10.1007/978-3-319-75361-4.

Barnes, S.A., Green, A. and de Hoyos, M. (2015), "Crowdsourcing and work: individual factors and circumstances influencing employability", New Technology, Work and Employment, Vol. 30 No. 1, pp. 16-31, doi: 10.1111/ntwe.12043.

Baron, R.M. and Kenny, D.A. (1986), "The moderator-mediator variable distinction in social psychology research: conceptual, strategic, and statistical considerations", Journal of Personality and Social Psychology, Vol. 51 No. 6, pp. 1173-1182.

Berg, J.M., Dutton, J.E. and Wrzesniewski, A. (2013), "Job crafting and meaningful work", in Dik, B.J., Byrne, Z.S. and Steger, M.F. (Eds), Purpose and Meaning in the Workplace, American Psychological Association, Washington DC, pp. 81-104, doi: 10.1007/s10894-015-9888-5.

Breugst, N., Domurath, A., Patzelt, H. and Klaukien, A. (2012), "Perceptions of entrepreneurial passion and employees' commitment to entrepreneurial ventures", Entrepreneurship: Theory and Practice, Vol. 36 No. 1, pp. 171-192, doi: 10.1111/j.1540-6520.2011.00491.x.

Caballer, A., Gracia, F. and Peiró, J.M. (2005), "Affective responses to work process and outcomes in virtual teams: effects of communication media and time pressure", Journal of Managerial Psychology, Vol. 20 Nos 3-4, pp. 245-260, doi: 10.1108/02683940510589037.

Cardon, M.S., Wincent, J., Singh, J. and Drnovsek, M. (2009), "The nature and experience of entrepreneurial passion”, Academy of Management Review, Vol. 34 No. 3, pp. 511-532, doi: 10.5465/AMR.2009.40633190.

Cardon, M.S., Gregoire, D.A., Stevens, C.E. and Patel, P.C. (2013), "Measuring entrepreneurial passion: conceptual foundations and scale validation", Journal of Business Venturing, Vol. 28 No. 3, pp. 373-396, doi: 10.1016/j.jbusvent.2012.03.003.

Cardon, M.S., Glauser, M. and Murnieks, C.Y. (2017), "Passion for what? Expanding the domains of entrepreneurial passion”, Journal of Business Venturing Insights, Vol. 8, pp. 24-32, doi: 10.1016/j. jbvi.2017.05.004.

Carlsson, B., Braunerhjelm, P., McKelvey, M., Olofsson, C., Persson, L. and Ylinenpää, H. (2013), "The evolving domain of entrepreneurship research”, Small Business Economics, Vol. 41, pp. 913-930.

Cavanaugh, M.A., Boswell, W.R., Roehling, M.V. and Boudreau, J.W. (2000), "An empirical examination of self-reported work stress among U.S. managers", Journal of Applied Psychology, Vol. 85 No. 1, pp. 65-74, doi: 10.1037/0021-9010.85.1.65.

Chang, S.J., Van Witteloostuijn, A. and Eden, L. (2010), "From the editors: common method variance in international business research", Journal of International Business Studies, Vol. 41 No. 2, pp. 178-184, doi: 10.1057/jibs.2009.88.

Chen, X.P., Yao, X. and Kotha, S. (2009), "Entrepreneur passion and preparedness in business plan presentations: a persuasion analysis of venture capitalists' funding decisions", Academy of Management Journal, Vol. 52 No. 1, pp. 199-214, doi: 10.5465/AMJ.2009.36462018.

Christian, M.S., Garza, A.S. and Slaughter, J.E. (2011), "Work engagement: a quantitative review and test of its relations with task and contextual performance", Personnel Psychology, Vol. 64, pp. 89-136.

Crawford, E.R., LePine, J.A. and Rich, B.L. (2010), "Linking job demands and resources to employee engagement and burnout: a theoretical extension and meta-analytic test", Journal of Applied Psychology, Vol. 95 No. 5, pp. 834-848, doi: 10.1037/a0019364. 
Davenport, T.H. and Cantrell, S. (2002), "The art of work: facilitating the effectiveness of high-end knowledge workers", Outlook Journal, available at: http://www.accenture.com/xd/xd.asp (accessed 10 April 2017).

De Simone, S. (2014), "Conceptualizing wellbeing in the workplace”, International Journal of Business and Social Science, Vol. 5 No. 12, pp. 118-122.

Deci, E.L. and Ryan, R.M. (1985), "The general causality orientations scale: self-determination in personality", Journal of Research in Personality, Vol. 19, pp. 109-134.

Demerouti, E., Nachreiner, F., Bakker, A.B. and Schaufeli, W.B. (2001), "The job demands-resources model of burnout", Journal of Applied Psychology, Vol. 86 No. 3, pp. 499-512.

Diamantopoulos, A. and Siguaw, J.A. (2000), Introducing LISREL, SAGE Publications, New York, NY.

Diener, E. (1984), "Subjective well-being”, Psychological Bulletin, Vol. 95 No. 3, pp. 542-575.

Dirks, K.T. and Ferrin, D.L. (2001), “The role of trust in organizational settings”, Organization Science, Vol. 12 No. 4, pp. 450-467, doi: 10.1287/orsc.12.4.450.10640.

Downes, P.E., Reeves, C.J., Mccormick, B.W., Boswell, W.R. and Butts, M.M. (2020), "Incorporating job demand variability into job demands theory: a meta-analysis", Journal of Management, (in press). doi: 10.1177/0149206320916767.

Dul, J., Ceylan, C. and Jaspers, F. (2011), 'Knowledge workers' creativity and the role of the physical work environment”, Human Resource Management, Vol. 50 No. 6, pp. 715-734, doi: 10.1002/ hrm.20454.

Fornell, C. and Larcker, D.F. (1981), "Evaluating structural equation models with unobservable variables and measurement error", Journal of Marketing Research, Vol. 18 No. 1, pp. 39-50, doi: 10.20546/ijcrar.2016.409.006.

Grant, A.M., Christianson, M.K. and Price, R.H. (2007), "Happiness, health, or relationships? Managerial practices and employee well-being tradeoffs", Academy of Management Perspectives, Vol. 21 No. 3, pp. 51-63.

Gruman, J.A. and Saks, A.M. (2011), "Performance management and employee engagement", Human Resource Management Review, Vol. 21 No. 2, pp. 123-136, doi: 10.1016/j.hrmr.2010.09.004.

Hackman, R.J. and Oldham, G.R. (1976), "Motivation through the design of work: test of a theory", Organizational Behavior and Human Performance, Vol. 166 No. 21, pp. 250-279.

Hakanen, J.J., Bakker, A.B. and Demerouti, E. (2005), "How dentists cope with their job demands and stay engaged: the moderating role of job resources”, European Journal of Oral Sciences, Vol. 113 No. 6, pp. 479-487, doi: 10.1111/j.1600-0722.2005.00250.x.

Hakanen, J.J., Perhoniemi, R. and Toppinen-Tanner, S. (2008), "Positive gain spirals at work: from job resources to work engagement, personal initiative and work-unit innovativeness", Journal of Vocational Behavior, Vol. 73, pp. 78-91.

Hallberg, U.E. and Schaufeli, W.B. (2006), "Same same" but different?", European Psychologist, Vol. 11 No. 2, pp. 119-127, doi: 10.1027/1016-9040.11.2.119.

Harju, L.K., Kaltiainen, J. and Hakanen, J.J. (2021), “The double-edged sword of job crafting: the effects of job crafting on changes in job demands and employee well-being", Human Resource Management, (in press). doi: 10.1002/hrm.22054.

Hauff, S., Guerci, M. and Gilardi, S. (2020), "Well-being-oriented HRM configurations: diffusion, contingencies, and outcomes", Evidence-based HRM: A Global Forum for Empirical Scholarship, Vol. 8 No. 3, pp. 253-271, doi: 10.1108/EBHRM-09-2019-0080.

Hessels, J., Rietveld, C.A. and van der Zwan, P. (2017), "Self-employment and work-related stress: the mediating role of job control and job demand", Journal of Business Venturing, Vol. 32, pp. 178-196.

Ho, V.T. and Astakhova, M.N. (2018), "Disentangling passion and engagement: an examination of how and when passionate employees become engaged ones", Human Relations, Vol. 71 No. 7, pp. 973-1000, doi: 10.1177/0018726717731505.

Passion for inventing 
IJEBR

27,9

Iacobucci, D. (2012), "Mediation analysis and categorical variables: the final Frontier", Journal of Consumer Psychology, Vol. 22 No. 4, pp. 582-594.

Johns, T. and Gratton, L. (2013), "The third wave of virtual work", Harvard Business Review, Vol. 91, pp. 1-2.

Kahn, W.A. (1990), "Psychological conditions of personal engagement and disengagement at work", Academy of Management Journal, Vol. 33 No. 4, pp. 692-724, doi: 10.5465/256287.

Kelliher, C. and Richardson, J. (2011), "Recent developments in new ways of organizing work", in Kelliher, C. and Richardson, J. (Eds), New Ways of Organizing Work, Routledge, London, pp. 13-17.

Kenney, M. and Zysman, J. (2016), "The rise of the platform economy", Issues in Science and Technology, Vol. 32 No. 3, pp. 61-69.

Kiggundu, M.N. (1981), "Task interdependence and the theory of job design", Academy of Management Review, Vol. 6 No. 3, pp. 499-508, doi: 10.1016/0030-5073(83)90118-6.

Macey, W.H. and Schneider, B. (2008), "The meaning of employee engagement", Industrial and Organizational Psychology, Vol. 1 No. 1, pp. 3-30, doi: 10.1111/j.1754-9434.2007.0002.x.

Mäkikangas, A., Schaufeli, W., Tolvanen, A. and Feldt, T. (2014), "Engaged managers are not workaholics: evidence from a longitudinal person-centered analysis", Revista de Psicología Del Trabajo y de Las Organizaciones, Vol. 29 No. 3, pp. 135-143, doi: 10.5093/tr2013a19.

Milanesi, M. (2018), "Exploring passion in hobby-related entrepreneurship: evidence from Italian cases”, Journal of Business Research, Vol. 92, pp. 423-430, doi: 10.1016/j.jbusres.2018.04.020.

Moriano, J.A., Molero, F., Topa, G. and Lévy Mangin, J.P. (2014), “The influence of transformational leadership and organizational identification on intrapreneurship", International Entrepreneurship and Management Journal, Vol. 10 No. 1, pp. 103-119, doi: 10.1007/s11365011-0196-x.

Murnieks, C.Y., Cardon, M.S. and Haynie, J.M. (2020), "Fueling the fire: examining identity centrality, affective interpersonal commitment and gender as drivers of entrepreneurial passion”, Journal of Business Venturing, Vol. 35 No. 1, p. 105909, doi: 10.1016/j.jbusvent.2018.10.007.

Newman, A., Obschonka, M., Moeller, J. and Chandan, G.G. (2021), "Entrepreneurial passion: a review, synthesis, and agenda for future research", Applied Psychology, Vol. 70 No. 2, pp. 816-860, doi: 10.1111/apps.12236.

Podsakoff, P. and Organ, D. (1986), "Self-reports in organizational research", Journal of Management, Vol. 12, pp. 531-544.

Pollack, J.M., Ho, V.T., O’Boyle, E.H. and Kirkman, B.L. (2020), "Passion at work: a meta-analysis of individual work outcomes", Journal of Organizational Behavior, Vol. 41 No. 4, pp. 311-331, doi: 10.1002/job.2434.

Rich, B.L., Lepine, J.A. and Crawford, E.R. (2010), "Job engagement: antecedents and effects on job performance”, Academy of Management Journal, Vol. 53 No. 3, pp. 617-635, doi: 10.5465/amj. 2010.51468988.

Ryan, R.M. and Deci, E.L. (2001), "On happiness and human potentials: a review of research on hedonic and eudaimonic well-being", Annual Review of Psychology, Vol. 52 No. 1, pp. 141-166.

Saks, A.M. and Gruman, J.A. (2014), "What do we really know about employee engagement?", Human Resource Development Quarterly, Vol. 25 No. 2, pp. 155-182, doi: 10.1002/hrdq.21187. 
Schaufeli, W.B. (2013), "What is engagement?”, in Truss, C., Alfes, K., Delbridge, R., Shantz, A. and Soane, E. (Eds), Employee Engagement in Theory and Practice, Routledge, London, pp. 29-49.

Schaufeli, W.B. and Salanova, M. (2007), "Work engagement: an emerging psychological concept and its implications for organizations", in Gilliland, S.W., Steiner, D.D. and Skarlicki, D.P. (Eds), Managing Social and Ethical Issues in Organizations, Information Age Publishing, Charlotte, NC, pp. 135-177.

Schaufeli, W.B. and Taris, T.W. (2014), "A critical review of the job demands-resources model: implications for improving work and health", in Bauer, G.F. and Hämmig, O. (Eds), Bridging Occupational, Organizational and Public Health: A Transdisciplinary Approach, Springer Science, New York, NY, pp. 43-68.

Schaufeli, W.B., Salanova, M., González-Romá, V. and Bakker, A.B. (2002), "The measurement of engagement and burnout: a two sample confirmatory factor analytic approach", Journal of Happiness Studies, Vol. 3 No. 1, pp. 71-92, doi: 10.1023/A:1015630930326.

Schaufeli, W.B., Bakker, A.B. and Salanova, M. (2006), "The measurement of work engagement with a short questionnaire", Educational and Psychological Measurement, Vol. 66 No. 4, pp. 701-716, doi: 10.1177/0013164405282471.

Schaufeli, W.B., Taris, T.W. and van Rhenen, W. (2008), "Workaholism, burnout, and work engagement: three of a kind or three different kinds of employee well-being?", Applied Psychology: An International Review, Vol. 57 No. 2, pp. 173-203, doi: 10.1111/j.1464-0597.2007. 00285.x.

Schneider, B., Yost, A.B., Kropp, A., Kind, C. and Lam, H. (2018), "Workforce engagement: what it is, what drives it, and why it matters for organizational performance", Journal of Organizational Behavior, Vol. 39, pp. 462-480, doi: 10.1002/job.2244.

Senior, J. (2014), "To the office, with love”, New York Magazine, pp. 1-4, 29 December, available at: https://www.thecut.com/2015/01/what-we-give-up-when-we-become-entrepreneurs.html.

Shuck, B., Ghosh, R., Zigarmi, D. and Nimon, K. (2012), "The jingle jangle of employee engagement", Human Resource Development Review, Vol. 12 No. 1, pp. 11-35, doi: 10.1177/1534484312463921.

Sobel, M.E. (1982), “Asymptotic confidence intervals for indirect effects in structural equation models", in Leinhardt, S. (Ed.), Sociological Methodology, Jossey Bass, San Francisco, CA, pp. 290-312.

Sonnentag, S. (2003), "Recovery, work engagement and proactive behavior: a new look at the interface between nonwork and work", Journal of Applied Psychology, Vol. 88 No. 3, pp. 518-528.

Spreitzer, G.M., Cameron, L. and Garrett, L. (2017), "Alternative work arrangements: two images of the new world of work", Annual Review of Organizational Psychology and Organizational Behavior, Vol. 4 No. 1, pp. 473-499, doi: 10.1146/annurev-orgpsych-032516-113332.

Steger, M.F., Dik, B.J. and Duffy, R.D. (2012), "Measuring meaningful work: the work and meaning inventory (WAMI)", Journal of Career Assessment, Vol. 20 No. 3, pp. 322-337, doi: 10.1177/ 1069072711436160.

Stenholm, P. and Nielsen, M.S. (2019), "Understanding the emergence of entrepreneurial passion: the influence of perceived emotional support and competences", International Journal of Entrepreneurial Behaviour and Research, Vol. 25 No. 6, pp. 1368-1388, doi: 10.1108/IJEBR-022018-0065.

Stephan, U. (2018), "Entrepreneurs' mental health and well-being: a review and research agenda", Academy of Management Perspectives, Vol. 32 No. 3, pp. 290-322.

Tims, M. and Bakker, A.B. (2010), "Job crafting: towards a new model of individual job redesign", $S A$ Journal of Industrial Psychology, Vol. 36 No. 2, pp. 1-9.

Trépanier, S.G., Fernet, C., Austin, S., Forest, J. and Vallerand, R.J. (2014), "Linking job demands and resources to burnout and work engagement: does passion underlie these differential relationships?”, Motivation and Emotion, Vol. 38 No. 3, pp. 353-366, doi: 10.1007/s11031-0139384-z.

\section{Passion for inventing}


IJEBR

27,9

Truss, C., Shantz, A., Soane, E., Alfes, K. and Delbridge, R. (2013), "Employee engagement, organisational performance and individual well-being: exploring the evidence, developing the theory", International Journal of Human Resource Management, Vol. 24 No. 14, pp. 2657-2669, doi: 10.1080/09585192.2013.798921.

Turner, T. and Pennington, W.W. (2015), "Organizational networks and the process of corporate entrepreneurship: how the motivation, opportunity, and ability to act affect firm knowledge, learning, and innovation”, Small Business Economics, Vol. 45 No. 2, pp. 447-463, doi: 10.1007/ s11187-015-9638-0.

Vallerand, R.J., Mageau, G.A., Ratelle, C., Léonard, M., Blanchard, C., Koestner, R., Gagné, M. and Marsolais, J. (2003), "Les passions de l'ame: on obsessive and harmonious passion", Journal of Personality and Social Psychology, Vol. 85 No. 4, pp. 756-767, doi: 10.1037/0022-3514.85.4.756.

Vallerand, R.J., Salvy, S.J., Mageau, G.A., Elliot, A.J., Denis, P.L., Grouzet, F.M.E. and Blanchard, C. (2007), "On the role of passion in performance", Journal of Personality, Vol. 75 No. 3, pp. 505-534, doi: 10.1111/j.1467-6494.2007.00447.x.

Van Beek, I., Hu, Q., Schaufeli, W.B., Taris, T.W. and Schreurs, B.H.J. (2012), "For fun, love, or money: what drives workaholic, engaged, and burned-out employees at work?", Applied Psychology, Vol. 61 No. 1, pp. 30-55, doi: 10.1111/j.1464-0597.2011.00454.x.

Van den Born, A. and Van Witteloostuijn, A. (2013), "Drivers of freelance career success", Journal of Organizational Behavior, Vol. 34, pp. 24-46, doi: 10.1002/job.

Venkataraman, S. (2019), "The distinctive domain of entrepreneurship research", in Katz, J.A. and Corbet, A.C. (Eds), Seminal Ideas for the Next Twenty-Five Years of Advances, Emerald Publishing, Bingley, pp. 5-20, doi: 10.1108/S1074-754020190000021009.

Warnick, B.J., Murnieks, C.Y., McMullen, J.S. and Brooks, W.T. (2018), "Passion for entrepreneurship or passion for the product? A conjoint analysis of angel and VC decision-making", Journal of Business Venturing, Vol. 33 No. 3, pp. 315-332, doi: 10.1016/j.jbusvent.2018.01.002.

Waterman, A.S. (1993), "Two conceptions of happiness: contrasts of personal expressiveness (eudaimonia) and hedonic enjoyment", Journal of Personality and Social Psychology, Vol. 64, pp. 678-691.

Wiklund, J., Nikolaev, B., Shir, N., Foo, M. and Bradley, S. (2019), "Entrepreneurship and well-being: past, present, and future", Journal of Business Venturing, Vol. 34 No. 4, pp. 579-588, doi: 10.1016/ j.jbusvent.2019.01.002.

Yalabik, Z.Y., van Rossenberg, Y., Kinnie, N. and Swart, J. (2015), "Engaged and committed? The relationship between work engagement and commitment in professional service firms", International Journal of Human Resource Management, Vol. 26 No. 12, pp. 1602-1621, doi: 10.1080/09585192.2014.953972.

\section{Corresponding author}

Ilona Toth can be contacted at: ilona.toth@lut.fi 


\section{Appendix}

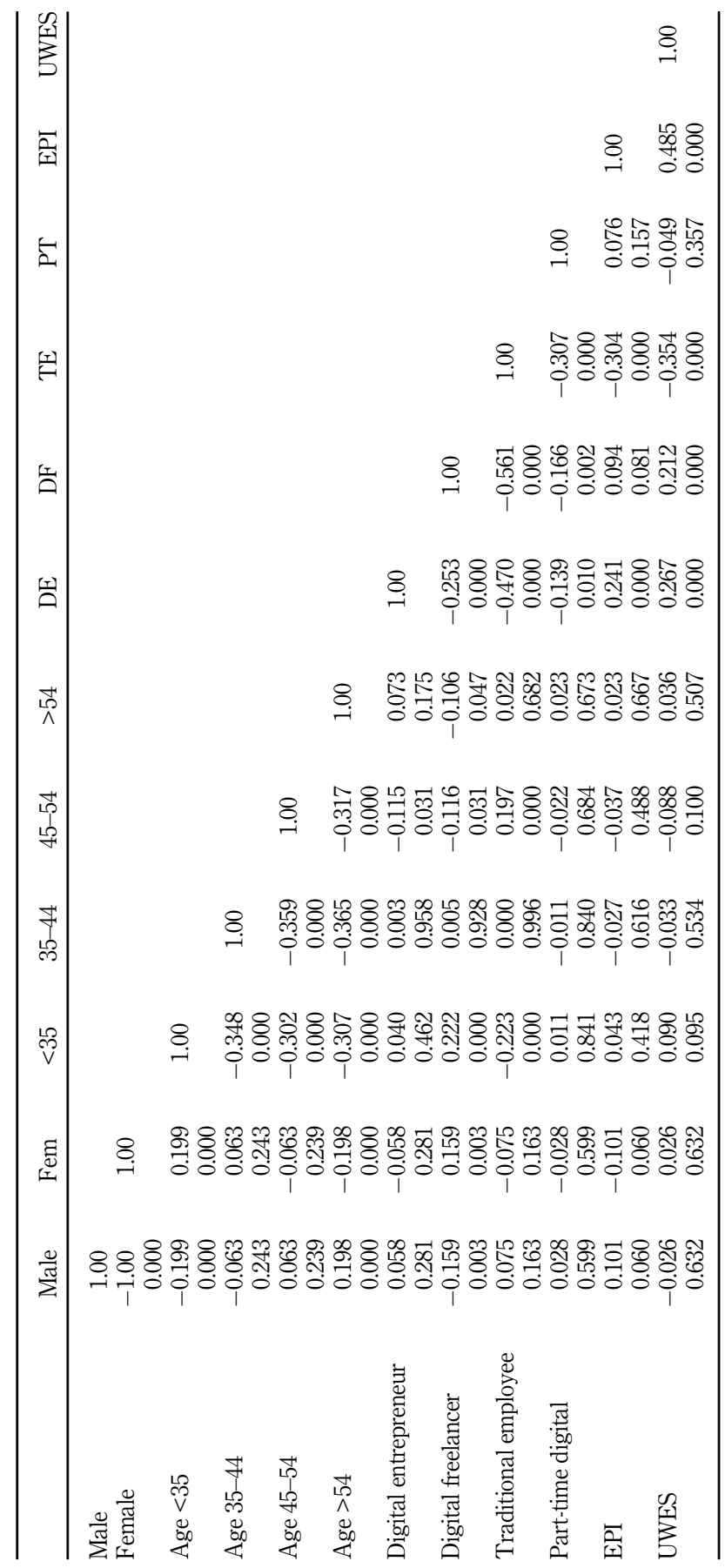

Passion for inventing

25

Table A1. Correlation matrix of all variables 